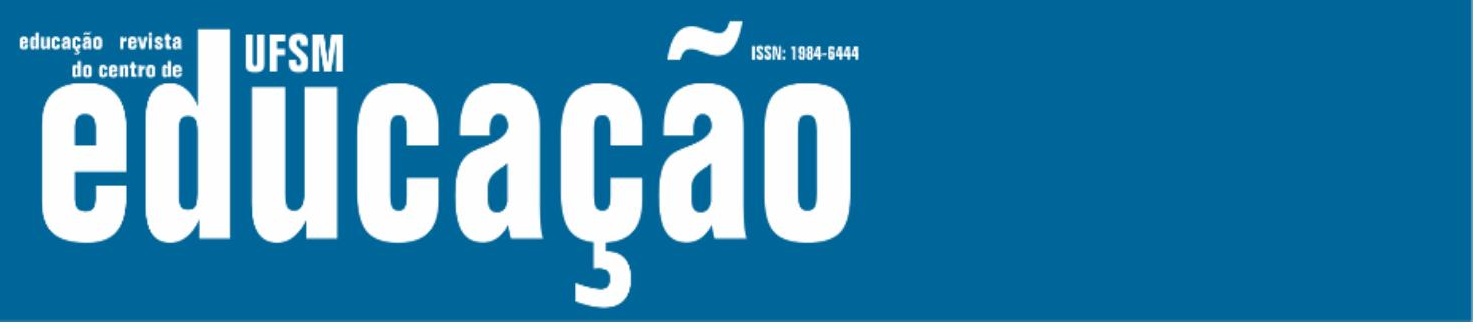

ISSN: 1984-6444 | http://dx.doi.org/10.5902/1984644458266

\title{
Entrevista com Sara York: A Travesti da/na educação Entrevista sobre atuação e vida da professora Sara Wagner York.
}

Sara York Interview: The Travesti in/of/from education Interview about the performance and life of teacher Sara Wagner York.

Entrevista a Sara York: La travesti de/em la educación Entrevista sobre la actuación y la vida de la profesora Sara Wagner York.

\section{Daniel Trajeiro Cara}

Cientista político Brasileiro, graduação em Ciências Sociais, Filosofia, Letras e Ciências Humanas na Universidade de São Paulo (1996-2000). Jornalista, entrevistador do canal do Youtube "Jornalistas Livres".

tojeira.cara@gmail.com

Sara Wagner York

Ativista pelos direitos LGBTQI+, faz parte da Associação Nacional de Travestis e Transexuais (Antra) no Brasil. Coeditora do livro Corpos transgressores: políticas de resistência.

sarayork.london@yahoo.co.uk

Recebido em 02 de outubro de 2020

Aprovado em 04 de novembro de 2020

Publicado em 21 de dezembro de 2020

\section{RESUMO}

Entrevista sobre a inserção de (minhas) experiências docências e pessoais, para compreender as distâncias e aproximações entre o campo educacional e um corpo travesti, foram fundantes para cartografar a vida social do corpo trans/travesti nos fluxos desse acesso à pós-graduação. Outra questão levantada foram as condições de possibilidade para o acesso e a permanência de pessoas trans/travestis na universidade, que des(a)fiam os limites da política de cotas. Os efeitos de nossas presenças em espaços públicos, entre eles a escola, geram um bolsão que produz e flerta com várias pedagogias e estéticas da existência. Entrevista feita via conferência pela internet, na plataforma Youtube onde participaram.

Palavras-chave: Travesti da educação; travestis na Educação; Cisgeneridade. 


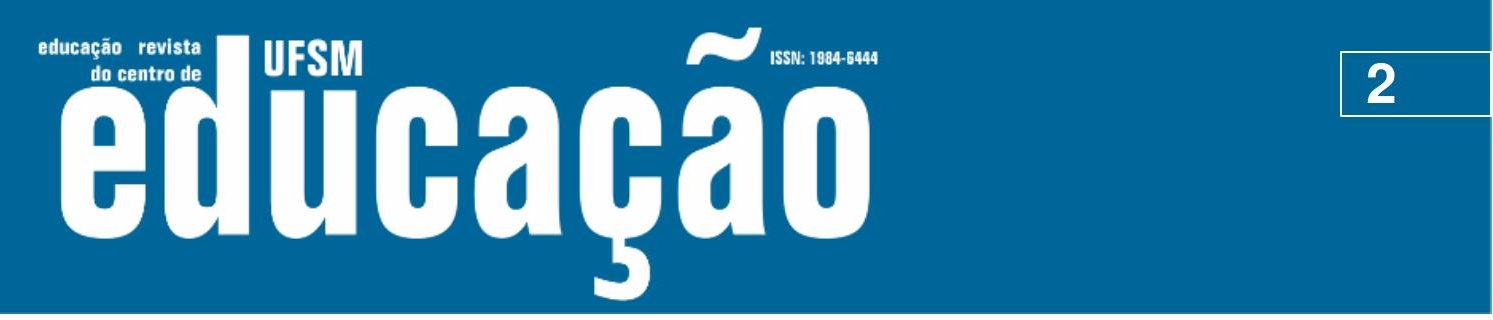

ISSN: 1984-6444 | http://dx.doi.org/10.5902/1984644458266

\section{ABSTRACT}

The interview about the insertion of (my) experiences, to understand the distances and approaches between the educational field and a travesti body, was fundamental to cartograph the social life of the body trans/travesti in the flows of this access to postgraduation. Another issue raised was the conditions of possibility of access and permanence of trans people in the university, challenging the boundaries of the policy of quotas. The effects of our presence in public spaces, the school among them, generate a concentration that produces and flirts with various pedagogies and aesthetics of existence. Interview made via internet conference, on the Youtube platform where they participated.

Keywords: Travesti in/of/from education; Trans/Travesti Quotas; Cisgenderism.

\section{RESUMEM}

Entrevista acerca de la inserción de (mis) experiencias, para entender las distancias y aproximaciones entre el campo educativo y un cuerpo travesti, fueron fundamentales para cartografiar la vida social del cuerpo trans/travesti en los flujos de este acceso a posgrado. Otro tema planteado fueron las condiciones de posibilidad para el acceso y permanencia de las personas trans/travestis en la universidad, desafiando los límites de la política de cuotas. Los efectos de nuestras presencias en los espacios públicos, incluida la escuela, generan un bolsón que produce y coquetea con diversas pedagogías estéticas y estéticas de la existencia. Entrevista realizada vía conferencia por internet, en la plataforma Youtube donde participaron.

Palavras-chave: Travesti de/em la educación; Difference; Cisgeneridad.

\section{Introdução}

Durante o período pandêmico de 2020, muitos sujeitos se viram sem famílias ou longe delas e sua forma de marcar seus conhecimentos pelo mundo foi escrevendo e/ou produzindo vídeos, conhecidos durante este período de livestreamings. Neste interim um diálogo com Daniel Cara, trouxe à baila a travestilidade, a transgeneridade e outras marcas da diferença que muitas vezes se torna letal no Brasil. A conversa ocorrida em junho de 2020 está condensada nestas linhas.

Daniel Cara: Boa noite a todas e todos! Mais um programa aqui no Jornalistas Livres, toda quinta-feira às oito e meia da noite. Nós entrevistamos uma pessoa que tem uma colaboração essencial sobre economia, política, educação... Enfim, sobretudo aquilo 


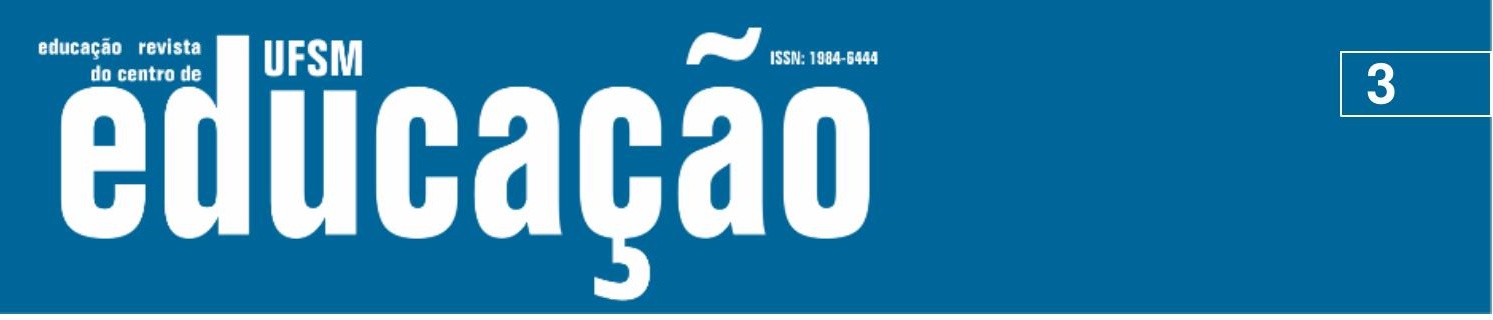

ISSN: 1984-6444 | http://dx.doi.org/10.5902/1984644458266

que melhora a qualidade de vida das pessoas, que atinge também a vida das pessoas, ou seja, questões que de fato importam para cada uma e para cada um de nós. E hoje eu tenho a honra de entrevistar a minha amiga, Sara Wagner York, eu vou apresentar aqui para vocês quem é a Sara que vocês vão ficar de queixo caído. A Sara Wagner York é mulher trans, travesti, professora, investigadora, pai, avó... Isso eu não sabia hein Sara? Depois você tem que contar isso para gente. Coreógrafa, Cabelereira, Maquiadora, Pedagoga, Múltipla e Subversiva e é como ela se apresenta e Mestre em Programa de Pós-Graduação em educação da Universidade da, aliás, da gloriosa Universidade do Estado do Rio de Janeiro, a UERJ, e ela tem uma dissertação que foi super elogiada que é intitulada "Tia, você é homem? Trans / da e na Educacão: Desafiando Cistemas" e aí o "Sis" de Sistemas é com "C", e ela vai falar sobre isso, e ocupando a pós-graduação, na qual nessa atividade, nessa tese, ela investigou as políticas de cotas para Transexuais e Travestis, nos programas de pós-graduação Brasileiros. Minha amiga Sara, Boa noite!

Sara Wagner: Boa Noite meu querido amigo, Daniel Cara, você que é a cara da nossa tentativa de trazer uma educação decente e muito obrigada pelo convite, pelo honroso convite. Impossível estar aqui e não agradecer a nossa maravilhosa "Rede da Campanha pelo Direito da Educação", que faz parte junto com tanta gente boa, tanta gente bacana, que pensa em educação para gente como eu e pra gente que nem é como eu e nem é como você. Gente que talvez vá chegar um dia e vá subverter muito mais do que isso que a gente vem tentado fazer! Muito obrigada pelo convite!

Daniel Cara: Ah, foi uma honra te entrevistar Sara, e acho que todo mundo aqui né, tá se perguntando nesse momento assim, qual é a tua trajetória? Como você chegou até aqui e o que você pode contar pra gente sobre a sua trajetória? Como você se tornou professora? Essa é primeira pergunta, qual foi o caminho que você trilhou?

Sara Wagner: Eh... Eu acho que eu chego Daniel, como eu gosto de dizer que eu sou uma Travesti DA EDUCAÇÃO e também sou uma Travesti NA EDUCAÇÃO hoje. Porque educar e trabalhar com as dinâmicas da educação eu já faço há muito tempo. 


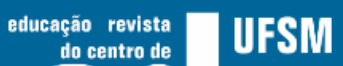

ISSN: 1984-6444 | http://dx.doi.org/10.5902/1984644458266

estava também trabalhando com educação, trabalhando com população de rua, trabalhando com adictos usuários de drogas ilícitas e essa foto deu uma circulada e apareceu uma coisa lá no meu Facebook dizendo: "Favor ligar para o Brasil urgente". "Ah, eu vou ligar pro Brasil? Não conheço esse povo. Não tenho parente lá, quero que todo mundo lá morra" (risos) Uma coisa bem assim, Olavista, "Eu não quero saber de nada dessa gente". Estava muito magoada pelo processo de perda do meu filho, mas aí eu falei: "Ah, eu vou ligar" e umas duas semanas depois eu liguei. E foi bem engraçado, porque eu tava bem me achando, assim né, "a estrela", aí eu ligo e falei:

"Alô"

"Alô, quem tá falando?"

"Aqui é a Sara, de Londres..."

E dando a carteirada já (risos)

E a pessoa do outro lado atende assim:

"Peraí, só um minutinho..."

E aí eu ouço aquele barulho de gente correndo, e aí a pessoa vai correndo e volta, quando ela volta, aí atende a pessoa:

"Alô"- E eu:

"Alô, quem é que tá falando - E aí a pessoa diz:

"Oi Pai, que saudade do seu cheiro meu pai..."

E era o meu filho.

Ele tinha me encontrado em um Facebook, numa foto de Elza Soares... (emocionada) 


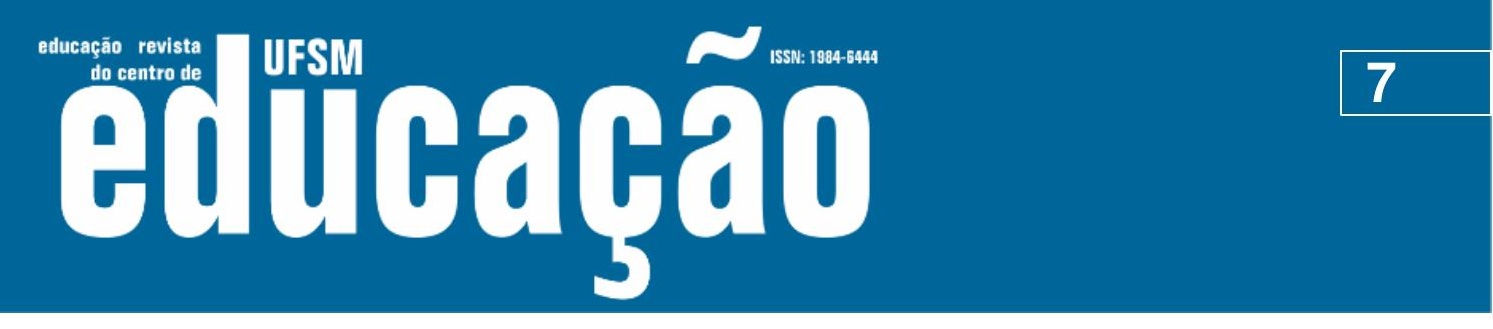

ISSN: 1984-6444 | http://dx.doi.org/10.5902/1984644458266

Daniel Cara : Ah, pode chorar...

Sara Wagner: É que toda a vez que eu falo disso, são coisas muito cortantes nas nossas vidas Daniel e que são banalizadas. Toda a vez que eu falava do meu filho e da ausência do meu filho, parecia que a minha dor era menor do que a de outras pessoas. Sabe? Toda a vez que eu falava da distância e da minha saudade, parecia que o fato de eu ter um filho, o meu filho valia menos do que os outros filhos. E eu sou uma mulher que durante esses anos, que passou esses anos procurando esse filho, acho que eu descobri os grandes mestres espirituais do Brasil; de Chico Xavier a João de Deus.

Então, todo lugar que me falavam: "Olha, tem uma senhora ou tem um senhor... A tia Neiva em Brasília, o Daime, a Ayhuasca, qualquer lugar que me dissessem assim, "olha tem uma senhora alí que sabe e que vê carta e que sabe como é que é". Todos esses lugares, quando diziam, eu estava lá. Assim eu conhecí Chico Xavier, assim eu conheci João de Deus, assim eu conheci Tia Neiva, assim eu conheci Manuel Jacinto Coelho, da Ordem Racional, da Cultura Racional, e assim, eu conheci os grandes líderes espirituais desse Brasil e procurando por um filho.

Em todos, o meu filho foi menor, porque era eu. (Emocionada)

E quando eu encontro o meu filho, já nesse momento, é, eu preciso fazer alguma coisa que faça isso algum significado e eu falei: "Eu vou voltar para o Brasil e vou refazer essa história de dar aula. Vou voltar, vou dar aula de Inglês, e dentro de uma escola. Eu quero ser uma Professora dentro de uma Escola". E vou contar essa história, até todo mundo saber que existem essas professoras (emocionada)

Daniel Cara: É isso aí Sara, é isso mesmo, e tem que contar essa história mesmo.

Sara Wagner: (emocionada)

Ah, olha Deniel, eu fiz toda uma maquiagem que agora tá indo... 


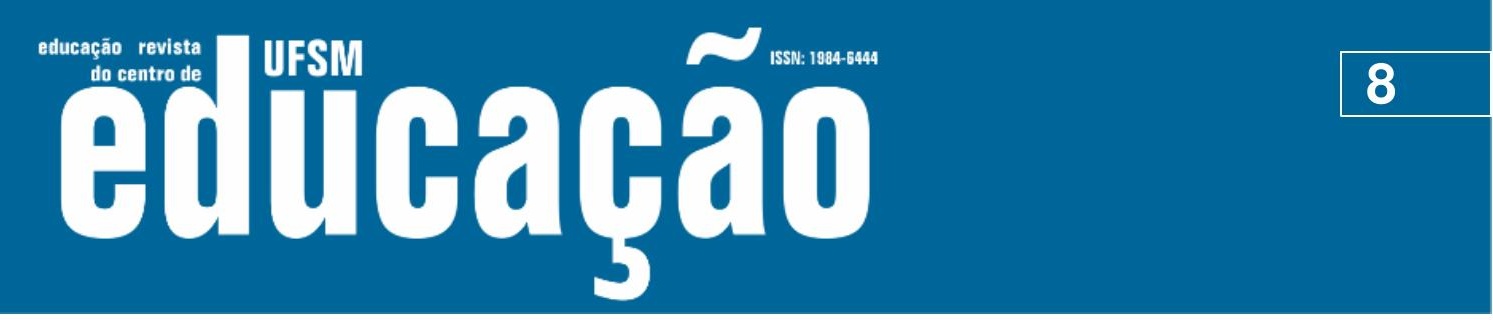

ISSN: 1984-6444 | http://dx.doi.org/10.5902/1984644458266

Daniel Cara: Que isso, você tá linda! Não se preocupe com isso. E a sua história faz com que você fique ainda mais bonita e ainda mais brilhante. Só para você aí dar uma respirada (...)

\section{- (CORTE PARA A DANIEL CARA CUMPRIMENTANDO OS PARTICIPANTES DA LIVE E APRESENTANDO AS SUAS REAÇÕES E COMENTÁRIOS) -}

Daniel Cara: Sara, a sua história é a nossa história, porque a sua história faz parte da construção de quem está aqui assistindo o programa, e de todas as suas alunas, e de todos os seus alunos, de todxs alunxs como você já me ensinou. (risos) E isso é importantíssimo, porque é através das histórias, já diriam os grandes historiadores, já diria o velho Marx também. Ontem eu dei aula de Marx e falei dessa questão, porque a história é na verdade aquilo que nos faz humanos. Porque a questão concreta dos seres humanos é que eles imprimem uma marca aqui nesse mundo, infelizmente muitas vezes essa marca é uma marca de destruição, mas você tem aí, uma enorme e bela marca de construção.

E aí me conta: Você se torna professora e como é ser Professora (...)

- (Sara Interrompe) -

Sara Wagner: (...) Ah, peraí, antes disso, eu preciso contar uma coisa antes... E aí, eu tenho que voltar pro Brasil, e quando eu volto para o Brasil, na minha cabeça tá tudo muito fácil: Eu chego aqui no Brasil, eu conheço alguém e aí alguém me indica para uma escola pública e eu começa a dar aulas; Tudo simples, tudo resolvido. E quando eu chego aqui no Brasil não era nada disso. Tinha que prestar um concurso público se quisesse estar la dentro, tinha que ser capacitada, tinha que passar por um processo exigido pelo MEC e o MEC não facilitava naquele momento, agora facilita, agora tem uma "outra história por ai", mas o MEC àquela altura, o MEC desse professor que a gente gosta, que é o Professo Fernando Haddad, era um MEC que ele exigia uma qualificação, ele tinha todo um traçado que era pensado "para esse 


\section{Aillbapẫ}

ISSN: 1984-6444 | http://dx.doi.org/10.5902/1984644458266

Sara Wagner: Eu atuo, mas hoje eu estou atuando só como Professora de ED pelo EAD da uerj. Estou professora Universitária a distância na UERJ. Estou colaborando com a 'informática na educação' com a Professor Ediméia Santos, Ediméia da ABECYBER né? Do GT vinte seis, então estou com esse pessoal. Sou orientanda do Professor Fernando Bocaí, que é uma sumidade no campo da pesquisa da subjetividade e da geração que discute isso tudo, e eu tenho que falar que sou amiga de Luly e da Inês Barbosa, se não, eu apanho. (risos)

E eu acho que chego na sala de aula, muito colonizada por esse sujeito que manda na sala de aula. O que significa isso Daniel? Na pós-graduação, eu sentei uma vez ao lado de um colega que falava: "Eu tô fazendo uma pesquisa, e falo palavrão com os alunos do Ensino Fundamental" E eu desconstruo isso para o aluno do Ensino Fundamental, eu explico como é que esse palavrão pode reverberar negativamente quando ele pensa uma série de coisas.

Quando eu chego na sala de aula, numa das primeiras aulas, eu escrevo lá vários palavrões na lousa, e vou perguntando quais eles conhecem e quais eles utilizam e isso numa sala, em uma mesa de pós-graduação ao meu lado, daí eu falei, "Cara, isso é um gênio. Isso é um gênio maravilhoso!" Porque você mostra aqui que é um privilégio do homem "cis-hetero", porque eu não posso fazer a metade disso. Se eu colocar um palavrão no quadro, eu nem volto para a sala de aula.

Então, assim, essas nuances que acontecem dentro da sala de aula e que não eram vistas começam a emergir muito fortemente, os meus alunos, por exemplo, eles me perguntam com muita facilidade:

"Ô Tia Sara, você é operada?"

No, início, eu fazia meio que desentendida, mas depois eu comecei a pensar:

"Operada de quê?" - e eles diziam: 


\section{تulloapẫ}

ISSN: 1984-6444 | http://dx.doi.org/10.5902/1984644458266

"Ah Professora, você sabe! Você fez aquele cirurgia de mudança de sexo?"

Eu falei - "Amor, isso é muito íntimo, você já perguntou a algum professor de matemática se ele já fez cirurgia de fimose?" (risos)

E aí eu escapava daquela. (risos). Porque aí também a gente começou a questionar:

"Professora, você já colocou tal coisa"

Daí eu dizia - "Você já perguntou isso pra alguma outra Professora"?

Daí eu comecei a perceber que existia espaço para "alguns corpos ocuparem uma sala de aula e não tinha para outros". Então, quem pensa em perguntar para o Daniel Cara do corpo dele? "E aí Daniel, você prótese?" Você faz isso? É... Você fez cirúrgia, sei la, hemorroida, né? Ninguém quer falar disso. Mas com esse corpo, como que é visto, digamos, "público", que é o corpo Trans na Educação, ele não tem os registros de um corpo privado, porque parece que tudo que é do Daniel, tem o "íntimo", tem o "privado"

e tem o "público". Então eu não posso fazer certas perguntas ao Daniel, porque subentendesse que: "peraí, isso é do campo da intimidade dele", mas como é com a Professora Sara, aí não, a esculhambação é aberta e aí a gente pode fazer o que a gente pode.

E essas nuances elas começaram na sala de aula a fazer muita diferença nas escolas em que eu passava, porque perguntava, escurecidamente, o que é que o aluno estava tentando dizer; $E$ com perguntas que também faziam essa sala de aula repensar as suas dinâmicas de ensino e de aprendizagem.

"Porque que a gente vai poder falar desse corpo público da Professora Sara, e a gente não pode falar desse corpo público da professora fulana ou professor fulano, porque o corpo desse professor é privado? Eu me lembro que isso se semelhava muito 


\section{OF HEM oltuarao}

ISSN: 1984-6444 | http://dx.doi.org/10.5902/1984644458266

temos alguma coisa. Nós temos alguma coisa, nós não temos tudo. Para alguns padrões de escola que nunca dialogaram conosco, por exemplo, essa escola ela nem existe, então esse aluno ele não vai existir.

Porque é importante a gente, aqui, trazer o corpo "Intersexo" e a Cassia entra tão fabulosamente trazendo essa memória e essa lembrança. Nós gravamos uma live com as mães da ABRAl e isso tá na página da ABRAl, que é a Associação Brasileira de Intersexo, e lá tem muita coisa falando disso. O mais interessante Daniel, é que estimasse, a Organização da Nações Unidas, estima que entre 0,5 e 1.7\% da população mundial seja Intersexo, ou seja, de cada cem pessoas que nós vemos, quase duas são Intersexo.

Mas como assim? Eu vou te perguntar: "Você já viu alguma pessoa de cabelo ruivo e que tenha cabelo ruivo na sua vida?"

Daniel Cara: Ah, sim, sim.

Sara Wagner: Então, você já conheceu alguém que tenha, por exemplo, vitiligo?

\section{Daniel Cara: Sim.}

Sara Wagner: Você já conheceu alguém que fosse... Bem, temos tantas amostragens que são muito superiores a essa. E que você já viu, ou seja, isso é MUITA GENTE. É muita gente, um corte de 0,7 de uma população toda, ser Intersexo no mundo, que tem esse corpo, e que esse corpo pode ser diferenciado em regime igonodal, ou seja, testículos e ovários, pode ser correlação a fenótipos , quer dizer "as estruturas externas", aquilo que pode parecer mais um pênis ou mais uma vagina, ou pode parecer uma outra proporção que a gente não conhece e isso está no nosso diaa-dia, no nosso cotidiano, está nas ruas do Brasil. E essa escola que a gente aprendeu que existia, ela não considera esse corpo! Ela não discute com esse corpo! Exatamente como a pornografia, eu pergunto a você: "Quando foi que você aprendeu 


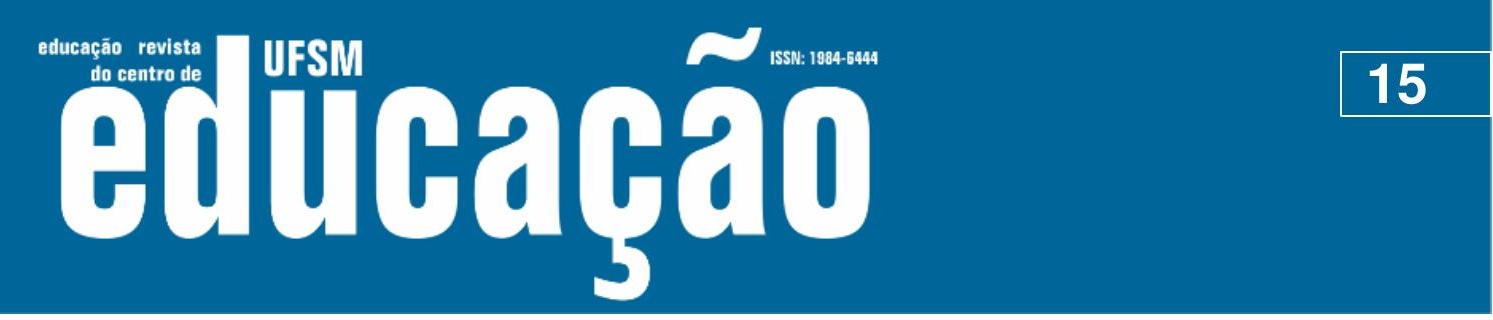

ISSN: 1984-6444 | http://dx.doi.org/10.5902/1984644458266

A gente tem todas as nossas 'nuances' das nossas vivências, e a gente tenta se aproximar, de alguma forma daquilo que é descrito, nas nossas ciências, biomedico-patologisantes muitas vezes, porque a medicina também faz esse favor para a gente, porque a medicina foi se desenhando com o que se falava: "Isso aqui é bom" automaticamente a outra coisa era tido como ruim. Então, um homem que tem um falo, um pênis de um jeito, aí fala: "Isso é okay", mas então, esse outro aqui, provavelmente deve ser ruim.

Todas essas nuances, elas vão dialogar muito com intersexo, com o que a gente vai chamar muito de "Marcas da Diferença", a diferença como "marca" social. Acho que é isso. (...) Muita coisa né? Muita coisa a gente tá falando...

Daniel Cara: Sim. Deixa eu contar aqui para algumas pessoas, porque algumas pessoas perguntaram qual foi o guia que você citou e eu aqui passei para a minha chefa, a Cátia Passos, aqui na técnica, para ela dispor o link aqui para as pessoas, mas o guia que a Sara cita, é o “Guia Nacional pelo Direito a Educação”, que trata da educação na Pandemia na perspectiva da inclusiva, inclusive é o primeiro guia, e a Sara pode contar isso pra gente, que ela é autora com dois nomes que se apresentam no guia. Então seria legal até pra gente você contar essa construção que foi feita na Campanha Nacional pelo Direito a Educação, que fica como um aprendizado e uma orientação para quem nos acompanha aqui Sara.

Sara Wagner: Exato. Eu acho que é fabuloso! O primeiro que eu tenho a dizer de que eu estou lá nesse guia, pensando esse guia com a Andressa Pelana, à partir da sua coordenação, mas também pensando junto com grandes nomes dessa área, e aí, a gente pode falar aqui da professora Liliana, a gente pode falar do Professor Wagner Santana, gente da melhor qualidade, e aí você estão vendo aí na tela. (...)

- (CORTE PARA A CAPA DO GUIA: “GUIA COVID 19 - EDUÇÃO ESPECIAL NA PERSPECTIVA INCLUSIVA - INFORME-SE E SAIBA COMO AGIR, COBRAR E TRABALHAR PELA EDUCAÇÃO DE MANEIRA COLABORATIVA) - 


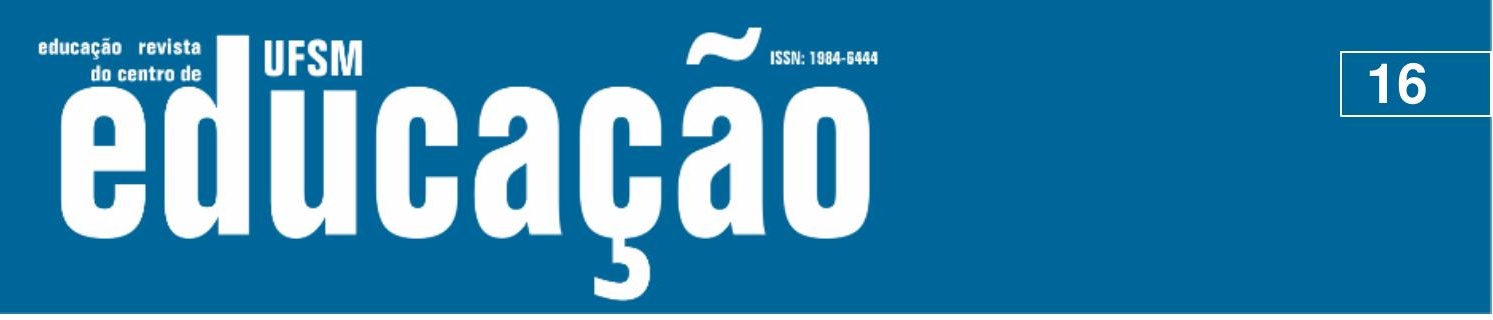

ISSN: 1984-6444 | http://dx.doi.org/10.5902/1984644458266

Sara Wagner: (...) Vocês podem ver que é um Guia de Educação Especial dentro de uma perspectiva inclusiva: “O quê que significa isso?” Pensar a criança com deficiência, mas não apenas isso, pensar em uma criança com deficiência, mas que também, segura nessa página Cátia, para a gente falar um pouquinho sobre essa parte (...)

- (CORTE PARA A SEGUNDA PÁGINA DO GUIA: “GUIA COVID 19 - EDUÇÃO ESPECIAL NA PERSPECTIVA INCLUSIVA - INFORME-SE E SAIBA COMO AGIR, COBRAR E TRABALHAR PELA EDUCAÇÃO DE MANEIRA COLABORATIVA) -

Sara Wagner: (...) e a gente pensar que essa criança é uma criança com deficiência, mas que pode e vai se tornar um adulto, que também tem as nuances dos direitos sexuais e reprodutivos, e em direito ao prazer, tem vários direitos que são assegurados a essa criança.

E aqui, a gente fez uma coisa meio ousada que foi trazer os dois nomes: Eu coloquei o nome "Sara Wagner York", que é meu nome no Instagram, no Facebook, no Midium, onde tem vários textos meus, mas também coloquei "Sara Wagner Pimenta Gonçalves Júnior, porquê Daniel? Porque Sara Wagner York é o meu nome social e isso é um nome que é muito utilizado por jovens e adolescentes no Ensino Fundamental e no Ensino Médio cada vez mais, e a escola precisa garantir que compreendem-se como Trans ou Travestis o direito ao uso do nome, porque a função do nome na escola é essa, que é trabalhar com as diferenças, é socializar a partir das diferenças e não uniformizar sujeitos e militarizar estruturas, como algumas pessoas tendem insistentemente em dizer. Então eu coloco os dois nomes pra dizer: "Olha, eu tenho dois nomes, um é social e o outro é o registro cível". E pela primeira vez a gente teve que justificar isso, e aí, muito prontamente eu fiz esse pedido a quem estava desenhando esse guia que é a Andressa, "Andressa, coloca um asterisco e explica que isso é uma parte política de inserção do nome social a pessoas Trans e Travestis". 


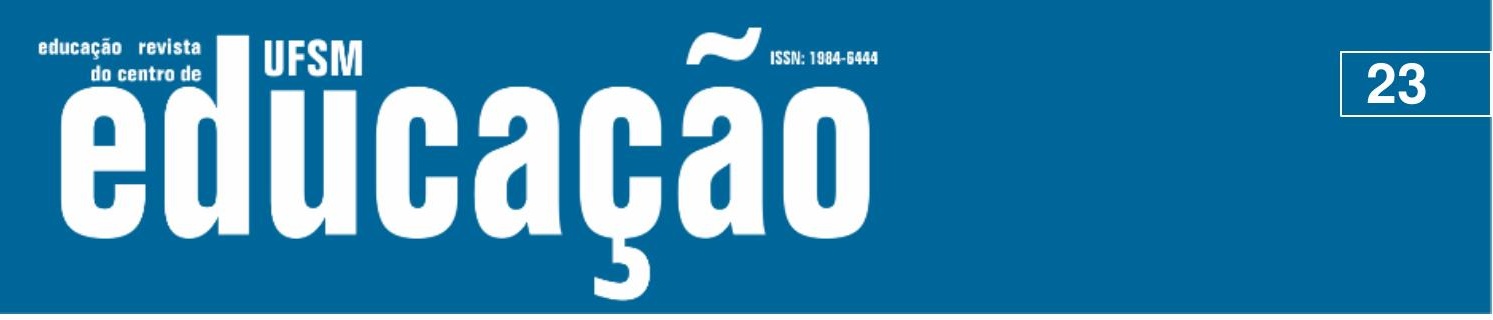

ISSN: 1984-6444 | http://dx.doi.org/10.5902/1984644458266

Medicina, amigos brancos, homens héteros, bonitos e todo mundo falava "ele merece, é muito difícil passar para medicina". Em 2016 um aluno meu me perguntou: "Ah Professora, como é que você vai dar aula de produção de texto se você não fez o ENEM? Você já fez o ENEM?", eu falei "Não" e ele falou; "Ah, então você tem que fazer o ENEM e aí você vai saber se realmente você vai dar conta ou não". E eu falei: "Ah, então tá, eu vou fazer o ENEM!".

E na época eu passei no ENEM (...)

\section{- (CORTE PARA SARA MOSTRANDO A FOLHA DE SUA APROVAÇÃO NO ENEM EM MEDICINA)}

Sara Wagner: (...) Então, tá aqui a prova, ó, eu passei no ENEM com o meu sobrenome. Consegue ver?

Daniel Cara: (...) Consigo ver. Medicina. Em São João Del Rey.

Sara Wagner: (...) Exatamente, em Medicina. E eu passei e pude dizer isso, eu sou uma Professora, e não é porque eu não tive uma outra opção não, eu não sou Pedagoga porque eu não tenho uma outra qualidade não. Eu escolhi não estar na Medicina, e escolheria MUITAS VEZES ser a pedagoga que eu sou, porque aqui eu aprendi como que se aprende esse trabalho tão artesanal que é "aprender para sí que é para aprender como lidar com o outro, para aprender como facilitar compreensões para quem a gente acha que, supostamente, a gente consegue educar".

Daniel Cara: Exatamente. Então, só aqui, para eu poder te dar um respiro, mostrar aqui como a nossa live está sendo acompanhada por muita gente (...)

- (CORTE PARA DANIEL CARA COMENTANDO AS INTERAÇÕES COM OS PARTICIPANTES DA LIVE QUE PARABENIZAM SARA PELO TRABALHO)

- (CORTE PARA SARA FALANDO DOS PARTICIPANTES DA LIVE ALEXANDRE NABOR E FABRÍCIO VILELA) 


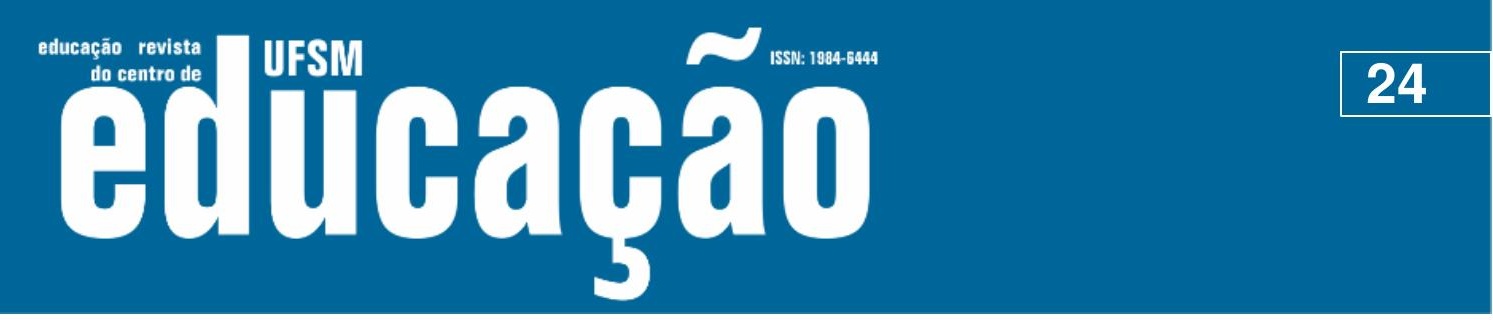

ISSN: 1984-6444 | http://dx.doi.org/10.5902/1984644458266

Sara Wagner: (...) Deixa eu só falar sobre dois que você agora citou. Alexandre Nabor, é uma pessoa importantíssima. O Alexandre ele tem um conceito que chama “cidadâniedade". A gente tem vários conceitos cidadania, de cidadanização, mas o conceito de cidadâniedade, que foi cunhado por Alexandre Nabor e interessantíssimo, porque ele diz, eu estou dizendo "a muito grosso modo para ser rápida": Ele diz que o Estado vem e dá uma série de coisas para o indivíduo, é só ele ir lá e tomar posse, então por exemplo: O Direito tá aí, é só você ir na Assitência Jurídica, e você ir lá e fazer o que tem pra você fazer, o problema é que algumas pessoas não se sentem DIGNAS de ser esse CIDADÃO, e aí não basta a cidadanização acontecer, e aí precisa se pensar a "cidadaniedade", que é o sujeito se sentir capaz de se sentir importante minimamente para lutar por essa cidadania que a gente pensa. Isso é fabuloso! E isso é um conceito de Alexandre Nabor.

O Fabrício Vilela, que é um parceiro lá dos estudos Queer, que é um intelectual e é mestre em história, e os estudos Queer e a perspectiva Travesti é exatamente isso, tá em moda agora, a gente falar esse nome, mas o que é isso? É exatamente esse modo de ser homem, de ser mulher, que muitas vezes, muitos de nós somos. Quem nunca ouviu uma mulher ou uma avó dizendo assim: "Eu sou muito mais homem do que esse fulano, ou um homem falando; 'Ah, eu faço igual mulher'; tudo isso são dinâmicas de uma performatividade de um roteiro de gênero que a gente não pensa. Mas que a todo tempo é reforçado em nossa cultura.

Daniel Cara: Muito bom, ó, uma outra pessoa aqui te parabenizando a Cassia Nonato, tá sinalizando muito aqui no nosso chat, comentando a sua fala, reforçando os argumentos que você traz, e também agradecer mais uma vez a Cassia.(...)

\section{- (CORTE PARA DANIEL CARA COMENTANDO AS INTERAÇÕES COM OS PARTICIPANTES DA LIVE QUE PARABENIZAM SARA PELO TRABALHO)}

Sara Wagner: (...) Temos que lembrar também Daniel, que a gente não quer criticar, a gente defende uma Escola, mas a gente defende uma Escola que é PÚBLICA, ela 


\section{Uism

ISSN: 1984-6444 | http://dx.doi.org/10.5902/1984644458266

- (CORTE PARA SARA MOSTRANDO A CAPA DO LIVRO CHAMADO "GÊNERO, SEXUALIDAE E GERAÇÃO - INTERSECCÇÕES NA EDUCAÇÃO E/M SAÚDE”)

Sara Wagner: (...) esse livro aqui, é um livro a qual eu tenho participação em um capítulo; que é o "Gênero, Sexualidade e Geração", que é organizado pelos Professores Fernando Bocaife, Felipe Carvalho, Nilton... (...)

- (CORTE PARA SARA MOSTRANDO A CAPA DO LIVRO CHAMADO "ESTUDOS SOBRE GÊNERO, IDENTIDADES, DISCURSO E EDUCAÇÃO - HOMENAGEM A JOÃO W. NERY")

Sara Wagner: (...) E esse livro aqui é uma homenagem a João W. Nery, organizado pelo Professor Dani, da Universidade do Mato Grosso e porque que eu estou trazendo esse pessoal? (...)

- (CORTE PARA SARA MOSTRANDO A CAPA DO LIVRO CHAMADO "NOS BABADOS DA ACADEMIA ")

Sara Wagner: (...) E esse livro, "Nos babados da Academia", organizado pela Ana Maria Barbará e por Sérgio Luiz Baptista da Silva, porque eu quero que todo mundo que esteja nos assistindo, Daniel, saiba que isso aqui é Universidade. A Universidade tem um monte e tem algumas pessoas que a gente nem sabe por quê existe, mas a Universidade tem tanta gente que a gente quer beijar na boca, a gente quer abraçar, a gente quer trazer para perto e essas pessoas existem. Gente como você, gente como o Fernando Horta, que bota a gente pra pensar lá na UNB, gente como as grandes pessoas da UNIRIO, eu eu falei agora pouco, a Luly, e (...) 


\section{工 WFM Eutoaráo}

ISSN: 1984-6444 | http://dx.doi.org/10.5902/1984644458266

- (CORTE PARA SARA MOSTRANDO A CAPA DO LIVRO CHAMADO "CORPOS TRANGRESSORES - POLÍTICAS DE RESISTÊNCIA")

Sara Wagner: (...) E esse aqui é um outro livro, esse aqui eu organizei também com Professores daqui, do Mato Grosso, do Rio de Janeiro, e aí um livro que eu estou lendo, que eu ganhei do Alexandre Magno, que é um parceiro (...)

\section{- (CORTE PARA SARA MOSTRANDO A CAPA DO LIVRO CHAMADO "EDUCAÇÃO CONTRA A BARBÁRIE”)}

Sara Wagner: (...) É esse aqui, não sei se você conhece?

Daniel Cara: Conheço. Tá aqui ó?!

- (CORTE PARA DANIEL CARA MOSTRANDO O LIVRO QUE ESTAVA ATRÁS DELE EM UMA ESTANTE, O MESMO CHAMADO "EDUCAÇÃO CONTRA A BARBÁRIE”)

Sara Wagner: (...) É esse aqui eu ainda estou lendo, que é do Fernando Cássio, que é idealizado por ele, e que tem um trecho lá seu, e me perco nessas aqui né? (...)

- (CORTE PARA SARA MOSTRANDO A CAPA DE DOS LIVROS DE "BELL HOOKS")

Sara Wagner: (...) Bell Hooks né? Para quem quer ler algo interessante, temos Bell Hooks e esse que eu fiz uma revisão muito carinhosa (...)

- (CORTE PARA SARA MOSTRANDO A CAPA DO LIVRO: “JACOB(Y) 'ENTRE OS SEXOS' E CARDIOPATIAS")

Sara Wagner: (...) que é a história do Jacob. O Jacob é esse bebê Daniel, que ele nasceu como uma cardiopatia e ele é intersexo. É um bebê que não tem uma genitália 


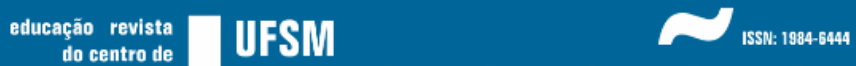

ISSN: 1984-6444 | http://dx.doi.org/10.5902/1984644458266

\section{Correspondência}

Daniel Trajeiro Cara - Universidade de São Paulo - R. da Reitoria, 374. Cidade Universitária, CEP 05508-220 Butantã, São Paulo, São Paulo, Brasil.

\section{(9) $(1) \Theta$}

This work is licensed under a Creative Commons Attribution-NonCommercial 4.0 International (CC BY-NC 4.0) 